\begin{tabular}{|c|l|}
\hline Title & $\begin{array}{l}\text { Fabrication and Characterization of CdS-Nanoparticle Mono- and Multilayers on a Self-A ssembled Monolayer of } \\
\text { A lkanedithiols on Gold }\end{array}$ \\
\hline Author(s) & Nakanishi, Takuya; Ohtani, Bunsho; Uosaki, Kohei \\
\hline Citation & $\begin{array}{l}\text { Journal of Physical Chemistry B, 102(9), 1571-1577 } \\
\text { https://doi.org/10.1021/jp973046w }\end{array}$ \\
\hline Issue Date & 1998-02-26 \\
\hline Doc URL & http://hdl.handle.net/2115/50244 \\
\hline Type & article \\
\hline File Information & JPCB102-9_1571-1577.pdf \\
\hline
\end{tabular}

Instructions for use 


\title{
Fabrication and Characterization of CdS-Nanoparticle Mono- and Multilayers on a Self-Assembled Monolayer of Alkanedithiols on Gold
}

\author{
Takuya Nakanishi, Bunsho Ohtani, and Kohei Uosaki* \\ Physical Chemistry Laboratory, Division of Chemistry, Graduate School of Science, Hokkaido University, \\ Sapporo 060, Japan
}

Received: September 17, 1997; In Final Form: December 16, 1997

\begin{abstract}
Mono- and multilayers of cadmium sulfide $(\mathrm{CdS})$ nanoparticles were fabricated on a gold substrate covered with alkanedithiol self-assembled monolayers (SAMs) by an alternate immersion of the substrate into ethanolic solutions of dithiol, i.e., 1,6-hexanedithiol or 1,10-decanedithiol, and dispersion of CdS nanoparticles (ca. 3 $\mathrm{nm}$ in diameter), the latter of which was prepared in sodium bis(2-ethylhexyl)sulfosuccinate (Aerosol OT, $\mathrm{AOT}) / \mathrm{H}_{2} \mathrm{O} /$ heptane reversed micelles. A layer-by-layer structure of dithiol SAM and CdS monolayer was confirmed with Fourier transform infrared reflection-absorption spectroscopy (FT-IRRAS) and X-ray photoelectron spectroscopy (XPS) at each step of composite-film preparation. It was revealed that CdS nanoparticles on SAMs were surrounded by AOT, which was then substituted by dithiols when the film was treated with the dithiol solution. The amount of $\mathrm{CdS}$ nanoparticles on the sample was measured by inductively coupled plasma mass spectrometry (ICP-MS) to be consistent with the above-mentioned monolayer structure. The photoinduced anodic current was observed when the composite film was immersed in an electrolyte solution containing triethanolamine as an electron donor. An action spectrum, which was quite similar to the absorption spectrum of $\mathrm{CdS}$ dispersion, indicates that the $\mathrm{CdS}$ nanoparticle keeps its size without mutual aggregation, and semiconducting properties even after being immobilized on the substrate.
\end{abstract}

\section{Introduction}

Semiconductor nanoparticles exhibit characteristic properties because of their quantum size and large proportion of surface atoms, which are significantly different from those of the corresponding bulk materials. ${ }^{1-4}$ Synthetic techniques developed and established so far provide a feasible way to prepare the nanoparticles as dispersions in organic and/or inorganic media or as aggregates. ${ }^{5-8}$ However, to develop novel electronic and/or optical devices making use of the mesoscopic physical and chemical characteristics of the semiconductor nanoparticles, it is necessary to attach them on solid surfaces, preferably in ordered structures without their mutual aggregation. Such composites may also give useful information on the electronic and physical properties of each nanoparticle, not of aggregates. A few reports showed attachment of the nanoparticles onto solid substrates covered with an anchoring layer such as Langmuir-Blodgett films, ${ }^{9}$ polyelectrolyte films, ${ }^{10,11}$ or selfassembled monolayer (SAM) films, ${ }^{12}$ which provides stable bonding between the substrate and nanoparticles. Among such films, SAMs are a particularly promising material for the construction of highly ordered and stable monolayers for chemical adherence of the nanoparticles onto their surfaces bearing various functional groups. Attachment of cadmium sulfide $(\mathrm{CdS}),{ }^{13,14}$ cadmium selenide $(\mathrm{CdSe}),{ }^{15}$ or lead sulfide $(\mathrm{PbS})^{16}$ nanoparticle monolayer onto a bifunctional 1,6-hexanedithiol SAM has been reported. A similar type of immobilization of CdS nanoparticles onto 3,3'-dithiobis(succinimidyl propionate) SAM through the amide bond has been also reported. ${ }^{17}$ Although these reports briefly discussed the surface structure of the CdS nanoparticles and/or the nature of the binding between SAM and semiconductor nanoparticles, ${ }^{13,14}$ the detailed characterization of surface structure, which may decisively influence the device property, has not yet been completed.

Recently, we have demonstrated that mono- and multilayer structures of CdS nanoparticles and dithiol SAMs are fabricated by a process of sequential immersion of substrate into dithiol solution and CdS-nanoparticle dispersion. The structural characteristics were outlined by using Fourier transform infrared reflection-absorption spectroscopy (FT-IRRAS) ${ }^{18}$ and X-ray photoelectron spectroscopy (XPS). ${ }^{19}$ Here, we report a further and detailed structural investigation of the composite layers by FT-IRRAS and XPS together with inductively coupled plasma mass spectrometry (ICP-MS). These measurements have confirmed the layer-by-layer structure of composite films of $\mathrm{CdS}$ nanoparticles and dithiol molecules. All the results were interpreted reasonably by a model proposed in our previous papers. Photocurrent measurements revealed that $\mathrm{CdS}$ nanoparticles in the film were still keeping their quantum-sized semiconductor properties as observed in dispersions and working as photosensitive semiconductor.

\section{Experimental Section}

CdS nanoparticles were prepared in reversed micelles following the method of Steigerwald et al. ${ }^{6}$ The preparation was operated under argon atmosphere. Typically, two $n$-heptane (spectrographic grade) solutions of $0.2 \mathrm{~mol} \mathrm{dm}^{-3}$ sodium bis(2-ethylhexyl)sulfosuccinate (Aerosol OT, AOT; see Figure 1) were prepared separately in Schlenk tubes. An aqueous solution of $\mathrm{Cd}\left(\mathrm{ClO}_{4}\right)_{2} \cdot 6 \mathrm{H}_{2} \mathrm{O}\left(0.4 \mathrm{~mol} \mathrm{dm}^{-3}\right)$ was added to one solution while an aqueous solution of $\mathrm{Na}_{2} \mathrm{~S} \cdot 9 \mathrm{H}_{2} \mathrm{O}\left(0.3 \mathrm{~mol} \mathrm{dm}^{-3}\right)$ was added to the other solution to give an $\left[\mathrm{H}_{2} \mathrm{O}\right] /[\mathrm{AOT}]$ ratio of 4 for both solutions. Both solutions were stirred vigorously for $1-2 \mathrm{~h}$. The cadmium solution was then added very slowly to 


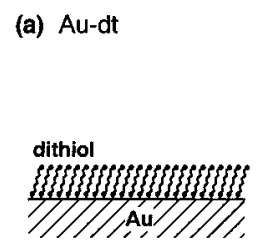

(b) Au-dt-CdS

(c) Au-dt-CdS-dt
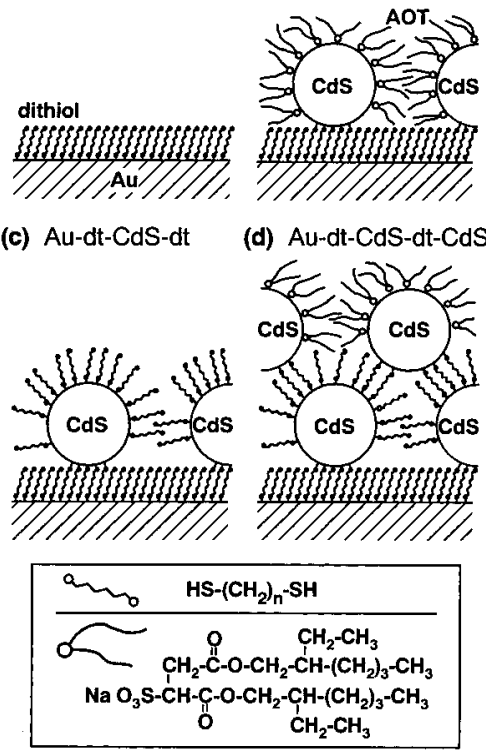

Figure 1. Schematic illustration of binding of the CdS nanoparticles from reversed micelles onto gold via dithiol and the formation of alternating layer-by-layer structure: (a) dithiol SAM on a gold substrate $(\mathrm{Au}-\mathrm{dt}) ;(\mathrm{b}) \mathrm{CdS}$ nanoparticles attached onto the SAM $(\mathrm{Au}-\mathrm{dt}-\mathrm{CdS})$; (c) adsorption of dithiol layers onto $\mathrm{CdS}$ nanoparticles $(\mathrm{Au}-\mathrm{dt}-\mathrm{CdS}-$ $\mathrm{dt})$; (d) formation of a second CdS-nanoparticle layer $(\mathrm{Au}-\mathrm{dt}-\mathrm{CdS}-$ $\mathrm{dt}-\mathrm{CdS})$. Each component is drawn in size according to the estimation from experimental results.

the sulfide solution in the dark using a dropping funnel. The resulting transparent and slightly yellowish solution was stirred in the dark for an additional $1 \mathrm{~h}$. Its absorption spectra were recorded on a Hitachi U-3300 spectrophotometer.

Gold substrates (thickness: $150 \mathrm{~nm}$ ) were prepared with a (111) orientation by vapor deposition under vacuum $\left(2 \times 10^{-4}\right.$ $\mathrm{Pa})$ at $300{ }^{\circ} \mathrm{C}$ onto microslide glass plates. The substrate for XPS measurements was precoated with 10 -nm-thick titanium as an adhesion layer. The 1,6-hexanedithiol and 1,10-decanedithiol SAMs were prepared by immersing the gold substrates in an ethanolic solution of the dithiol $\left(1 \mathrm{mmol} \mathrm{dm}^{-3}\right)$ for $12-24 \mathrm{~h}$. Hereafter, the sample thus prepared is called $\mathrm{Au}-$ dt. The immersed samples were rinsed with ethanol several times and then dried in an argon stream. The CdS-nanoparticle layers were prepared by immersing $\mathrm{Au}-\mathrm{dt}$ in a CdS-nanoparticle dispersion for $12-24 \mathrm{~h}$, rinsed with heptane several times, and then dried in an argon stream $(\mathrm{Au}-\mathrm{dt}-\mathrm{CdS})$. Additional layers of the dithiol and $\mathrm{CdS}$ nanoparticle were deposited on $\mathrm{Au}-$ $\mathrm{dt}-\mathrm{CdS}$ by consecutive immersion into the solution of dithiol $(\mathrm{Au}-\mathrm{dt}-\mathrm{CdS}-\mathrm{dt})$ and the dispersion of $\mathrm{CdS}$ nanoparticle $(\mathrm{Au}-$ $\mathrm{dt}-\mathrm{CdS}-\mathrm{dt}-\mathrm{CdS})$. The sequence of the preparation of $\mathrm{Au}-$ $\mathrm{dt}, \mathrm{Au}-\mathrm{dt}-\mathrm{CdS}, \mathrm{Au}-\mathrm{dt}-\mathrm{CdS}-\mathrm{dt}$ and $\mathrm{Au}-\mathrm{dt}-\mathrm{CdS}-\mathrm{dt}-\mathrm{CdS}$ is schematically shown in Figure 1.

FT-IR spectra were taken using a Bio-Rad FTS-30 spectrometer equipped with a liquid-nitrogen-cooled $\mathrm{HgCdTe}$ detector. Reflection-absorption (RA) spectra were obtained by using a specular reflectance accessory in which the angle between the p-polarized IR probe beam and the substrate $(20 \mathrm{~mm} \times 26 \mathrm{~mm})$ was $10^{\circ}$. The RA and transmission spectra were accumulated for 1024 and 64 scans, respectively. The light path in the spectrometer including the sample chamber was purged by dry air.

XPS measurements were performed on a Rigaku XPS-7000 spectrometer using an $\mathrm{Mg} \mathrm{K} \alpha \mathrm{X}$-ray source. Base pressure in the analysis chamber was $5 \times 10^{-7} \mathrm{~Pa}$. Angle-resolved (AR) XP spectra were obtained by varying the angle between the

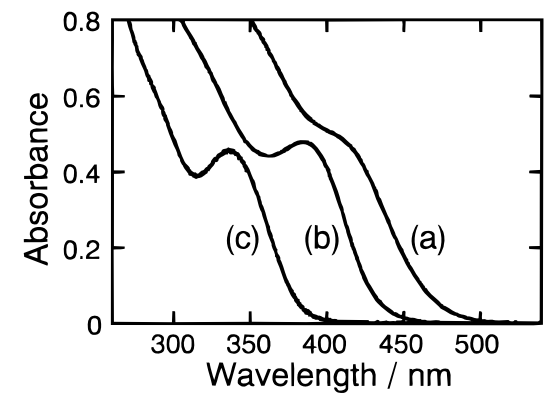

Figure 2. Absorption spectra of $\mathrm{CdS}$ nanoparticles in heptane prepared with different $\left[\mathrm{H}_{2} \mathrm{O}\right] /[\mathrm{AOT}]$ ratios: (a) 5.5 , (b) 4.0 , and (c) 2.7 . Concentration of CdS in each dispersion was ca. $5 \times 10^{-4} \mathrm{~mol} \mathrm{dm}^{-3}$.

surface and analyzer from $90^{\circ}$ to $10^{\circ}$. To evaluate the damage of the sample by X-ray during the measurement, the spectrum at the takeoff angle of $90^{\circ}$ was recorded twice, at the beginning and the end of each measurement of samples. Wide scans were carried out with 50-eV pass energy, 25-W electron-beam power, and a resolution of $0.8 \mathrm{eV}$. Narrow-scan spectra of the $\mathrm{Cd} 3 \mathrm{~d}$, $\mathrm{S} 2 \mathrm{p}, \mathrm{O} 1 \mathrm{~s}, \mathrm{C} 1 \mathrm{~s}$, and $\mathrm{Au} 4 \mathrm{f}$ regions were taken with $15-\mathrm{eV}$ pass energy, 100-W electron-beam power, and a resolution of $0.1 \mathrm{eV}$. All the binding energy was calibrated with an $\mathrm{Au} 4 \mathrm{f}_{7 / 2}$ peak at $84.0 \mathrm{eV}$. Narrow-scan spectra of the Cd 3d, S 2p, O $1 \mathrm{~s}$, and $\mathrm{C} 1 \mathrm{~s}$ regions were analyzed as follows. A linear background spectrum was assumed for each region and subtracted before curve-fitting. The fitting was carried out by using Gaussian shaped peaks with fixed fwhm (full width at halfmaximum) for each element. The relative molar amount of elements was determined from the integrated peak areas and corrected with experimentally derived atomic sensitivity factors. ${ }^{20,21}$

ICP-MS measurements were carried out with a HewlettPackard HP 4500 spectrometer for $\mathrm{Cd}(\mathrm{m} / \mathrm{z}=111$ and 114). Sample solutions were prepared by dissolving the films prepared on substrates $(10 \mathrm{~mm} \times 20 \mathrm{~mm})$ into $0.1 \mathrm{mmol} \mathrm{dm}^{-3}$ nitric acid. Milli-Q water was used throughout the measurement. Contamination of $\mathrm{Cd}$ in the water was below the detection limit.

Photoelectrochemical measurements were carried out in a three-electrode cell equipped with a quartz window. A platinum wire and an $\mathrm{Ag} / \mathrm{AgCl}$ (saturated $\mathrm{NaCl}$ ) electrode were used as a counter and a reference electrode, respectively. The solution consisted of $0.5 \mathrm{~mol} \mathrm{dm}^{-3} \mathrm{Na}_{2} \mathrm{SO}_{4}$ as supporting electrolyte and $20 \mathrm{mmol} \mathrm{dm}^{-3}$ triethanolamine as electron donor. The electrode potential was kept at $0 \mathrm{mV}$ vs $\mathrm{Ag} / \mathrm{AgCl}$ where the dark current was below the detection limit. An Ushio UXL500D-0 500-W xenon lamp with a Ritsu MC-25NP monochromator was used for monochromatic illumination. The light intensity was calibrated using an Anritsu ML94A/MA97B optical power meter. All photocurrent responses were recorded using a Toho Technical Research potentiostat/galvanostat 2001 and a Rika Denki RW-11T $X-Y$ recorder.

\section{Results and Discussion}

Absorption Spectra of CdS-Nanoparticle Dispersions. Representative absorption spectra of CdS nanoparticles dispersed in heptane solutions are shown in Figure 2. A decrease in the $\left[\mathrm{H}_{2} \mathrm{O}\right] /[\mathrm{AOT}]$ ratio in the preparation process resulted in a blue shift of both the absorption maximum and the absorption edge. This agrees well with the results by Steigerwald et al. ${ }^{6}$ A blue shift of the absorption maximum and the absorption edge is caused by quantum confinement. The smaller the particle size, the greater the blue shift. CdS nanoparticles showing an absorption maximum at $310 \mathrm{~nm}$ were obtained with an $\left[\mathrm{H}_{2} \mathrm{O}\right] /$ 


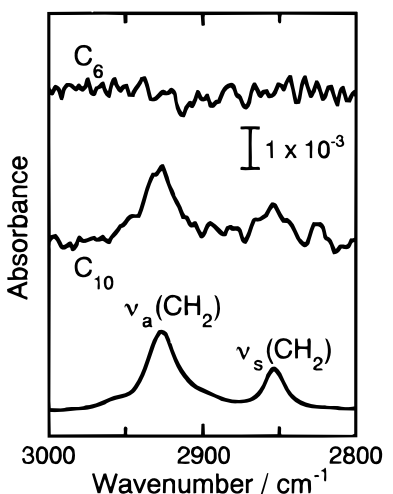

Figure 3. $\mathrm{CH}$ stretching region of FT-IRRA spectra of the hexanedithiol $\left(\mathrm{C}_{6}\right)$ and the decanedithiol $\left(\mathrm{C}_{10}\right)$ SAMs $(\mathrm{Au}-\mathrm{dt})$, together with an FT-IR transmission spectrum of decanedithiol (bottom).

[AOT] ratio of 1 , while those showing a shoulder in the absorption spectrum at $450 \mathrm{~nm}$ were obtained with an $\left[\mathrm{H}_{2} \mathrm{O}\right] /$ [AOT] ratio of 10 . The absorption maximum at $310 \mathrm{~nm}$ and the shoulder at $450 \mathrm{~nm}$ correspond to about 1 and $5 \mathrm{~nm}$ in diameter, respectively. ${ }^{22}$ Those diameters of CdS nanoparticles agreed with the expected diameter of "water pool" in the reversed micelle. ${ }^{6,23}$ Thus, we have confirmed that the size of particles can be controlled easily by changing the $\left[\mathrm{H}_{2} \mathrm{O}\right] /[\mathrm{AOT}]$ ratio. The absorption spectrum of $\mathrm{CdS}$ nanoparticles used mainly in this study is given by line b. The absorption maximum at $390 \mathrm{~nm}$ corresponds to a particle diameter of ca. $3 \mathrm{~nm}^{22}$

Structural Investigation of the Composite Layers by FTIRRAS. IR measurements gave information of structural characteristics of dithiol and AOT molecules. Figure 3 shows the $\mathrm{CH}$ stretching region of FT-IRRA spectra of hexanedithiol and decanedithiol SAMs $(\mathrm{Au}-\mathrm{dt})$. For decanedithiol SAM, asymmetric and symmetric methylene stretches, $v_{\mathrm{a}}\left(\mathrm{CH}_{2}\right)$ and $v_{\mathrm{s}}\left(\mathrm{CH}_{2}\right)$, were observed at 2926 and $2854 \mathrm{~cm}^{-1}$, respectively, which were almost the same as those observed in a transmission spectrum of decanedithiol. It has been reported that the densely packed SAMs show a shift of the IR peak position to lower wavenumbers (2920 and $2851 \mathrm{~cm}^{-1}$, respectively) $)^{24}$ and give an absorbance of $v_{\mathrm{s}}\left(\mathrm{CH}_{2}\right)$ of $5.5 \times 10^{-4}$, which is a little larger than that of the present measurement, $6 \times 10^{-4}$. These facts suggest that the degree of ordering of SAM was a little low. For hexanedithiol, methylene stretching peak positions could not be determined because of low signal-to-noise ratio. Similar behavior, depending on the length of the alkyl chain, has been observed with the alkanethiol SAMs. ${ }^{24}$

The profile of spectrum of $\mathrm{Au}-\mathrm{dt}-\mathrm{CdS}$ is significantly different from that of $\mathrm{Au}-\mathrm{dt}$; new absorption bands appeared in the mid-IR region. Although the spectra of samples using hexanedithiol and decanedithiol as binding layers seemed a little different, the difference spectra between $\mathrm{Au}-\mathrm{dt}-\mathrm{CdS}$ and $\mathrm{Au}-$ $\mathrm{dt}$ using hexanedithiol and decanedithiol $\left(\mathrm{C}_{6}(\mathrm{a})\right.$ and $\left.\mathrm{C}_{10}(\mathrm{a})\right)$ resemble each other and coincide with the transmission spectrum of AOT, as shown in Figure 4. The peak assignment is as follows. Bands at 2961 and $2875 \mathrm{~cm}^{-1}$ are attributed to the asymmetric and symmetric methyl stretches $v_{\mathrm{a}}\left(\mathrm{CH}_{3}\right)$ and $v_{\mathrm{S}^{-}}$ $\left(\mathrm{CH}_{3}\right)$, respectively. Bands at 2932 and $2862 \mathrm{~cm}^{-1}$ are assigned to $v_{\mathrm{a}}\left(\mathrm{CH}_{2}\right)$ and $v_{\mathrm{s}}\left(\mathrm{CH}_{2}\right)$, respectively. In the mid-IR region, the carbonyl stretch $v(\mathrm{C}=\mathrm{O})$ at $1736 \mathrm{~cm}^{-1}$, ester stretch $v(-\mathrm{C}$ $(=\mathrm{O})-\mathrm{O}-\mathrm{C}-$ ) at $1246 \mathrm{~cm}^{-1}$, and the asymmetric and symmetric stretches of the sulfonate $v_{\mathrm{a}}\left(\mathrm{SO}_{2}\right)$ and $v_{\mathrm{s}}\left(\mathrm{SO}_{2}\right)$ at 1160 and $1052 \mathrm{~cm}^{-1}$ were observed. A broad peak around $1600 \mathrm{~cm}^{-1}$ is assignable to water included in reversed micelles, though we have no additional information on the water presumably

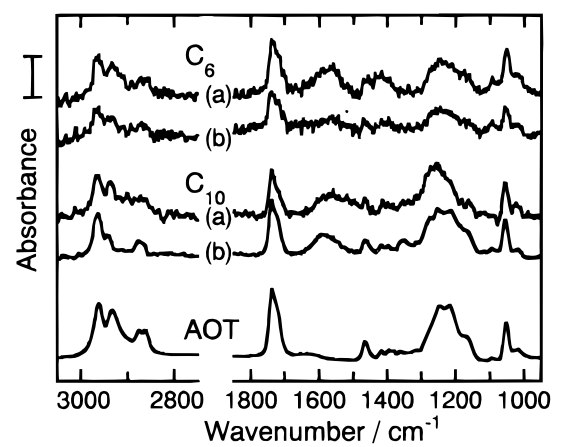

Figure 4. Comparison of difference FT-IRRA spectra (upper four spectra) and FT-IR transmission spectrum of AOT (bottom). Spectra $\mathrm{C}_{6}(\mathrm{a})$ and $\mathrm{C}_{10}$ (a) are the spectral differences between $\mathrm{Au}-\mathrm{dt}-\mathrm{CdS}$ and $\mathrm{Au}-\mathrm{dt}$ using hexanedithiol and decanedithiol as binding layers, respectively. Spectra $\mathrm{C}_{6}(\mathrm{~b})$ and $\mathrm{C}_{10}(\mathrm{~b})$ correspond to the difference between $\mathrm{Au}-\mathrm{dt}-\mathrm{CdS}-\mathrm{dt}-\mathrm{CdS}$ and $\mathrm{Au}-\mathrm{dt}-\mathrm{CdS}-\mathrm{dt}$ using hexanedithiol and decanedithiol as binding layers, respectively. A bar shows an absorbance of $1 \times 10^{-3}$ for RA spectra.

remaining on the composite films. The almost identical intensities of the AOT peaks for both SAMs were obtained, suggesting that the amount of CdS nanoparticle, in the first layer, on the SAMs is independent of the chain length of the SAMs.

It is noticeable that after further immersion of the $\mathrm{Au}-\mathrm{dt}-$ $\mathrm{CdS}$ to the dithiol solution, these AOT bands disappeared almost completely while the methylene stretching bands $v_{\mathrm{a}}\left(\mathrm{CH}_{2}\right)$ and $v_{\mathrm{s}}\left(\mathrm{CH}_{2}\right)$ modes at 2926 and $2854 \mathrm{~cm}^{-1}$, respectively, appeared again. On sequential immersion in the $\mathrm{CdS}$ nanoparticle dispersion and the dithiol solution, the AOT peaks alternately appeared and disappeared together with a gradual increase in intensity of the dithiol peaks. ${ }^{18}$ The difference spectra between the $\mathrm{Au}-\mathrm{dt}-\mathrm{CdS}-\mathrm{dt}-\mathrm{CdS}$ and the $\mathrm{Au}-\mathrm{dt}-\mathrm{CdS}-\mathrm{dt}$ using hexanedithiol and decanedithiol as binding layers $\left(\mathrm{C}_{6}(\mathrm{~b})\right.$ and $\left.\mathrm{C}_{10}(\mathrm{~b})\right)$ are also shown in Figure 4. The intensities of the AOT peaks for $\mathrm{C}_{6}(\mathrm{~b})$ relative to those for $\mathrm{C}_{6}(\mathrm{a})$ in Figure 4 were $0.7-$ 0.8 , indicating that the second $\mathrm{CdS}$ layer contains slightly smaller amounts of CdS compared with the first layer. On the other hand, the corresponding ratio for decanedithiol was almost unity; the intensities of peaks in $\mathrm{C}_{10}$ (b) were almost the same as in $\mathrm{C}_{10}(\mathrm{a})$. Such chain-length-dependent difference is explained by the possible increase in flexibility of the alkyl chains with chain length; decanedithiol molecules on the first CdS layer may feasibly catch another CdS nanoparticle by changing its shape more flexibly compared with hexanedithiol.

These IRRAS results indicate that AOT molecules surrounding $\mathrm{CdS}$ are substituted by dithiols, as schematically shown in parts $\mathrm{b}$ and $\mathrm{c}$ of Figure 1. An increase in the $v\left(\mathrm{CH}_{2}\right)$ peak intensity for both the hexanedithiol and the decanedithiol SAMs, as reported previously, ${ }^{18}$ is also consistent with the proposed mechanism. Further immersion in the $\mathrm{CdS}$ nanoparticle dispersions results in the attachment of AOT-capped CdS, as illustrated in Figure 1d.

Structural Investigation of the Composite Layers by XPS. Wide-scan XP spectra of the samples with hexanedithiol as a binding layer are shown in Figure 5. The spectra $a-d$ correspond to the samples $\mathrm{a}-\mathrm{d}$ illustrated in Figure 1. In addition to peaks assigned to the substrate $\mathrm{Au}$, peaks corresponding to $\mathrm{C}$ and $\mathrm{S}$ were observed for $\mathrm{Au}-\mathrm{dt}$ (dithiol SAM), indicating the presence of the dithiol molecules. Further appearance of $\mathrm{Cd}$ and $\mathrm{O}$ peaks in $\mathrm{Au}-\mathrm{dt}-\mathrm{CdS}$ spectra shows qualitatively the presence of $\mathrm{CdS}$ and AOT on the substrate. Further immersion processes of $\mathrm{Au}-\mathrm{dt}-\mathrm{CdS}$ in dithiol solution $(\mathrm{Au}-\mathrm{dt}-\mathrm{CdS}-\mathrm{dt})$ and then in $\mathrm{CdS}$-nanoparticle dispersion $(\mathrm{Au}-\mathrm{dt}-\mathrm{CdS}-\mathrm{dt}-\mathrm{CdS})$ led to removal and recovery, respec- 


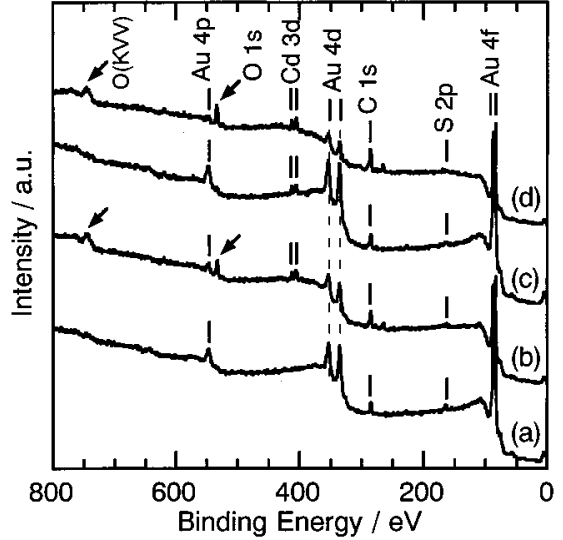

Figure 5. Wide-scan XP spectra of the composite films, where hexanedithiol was used as a binding layer: (a) $\mathrm{Au}-\mathrm{dt}$; (b) $\mathrm{Au}-\mathrm{dt}-$ $\mathrm{CdS}$; (c) $\mathrm{Au}-\mathrm{dt}-\mathrm{CdS}-\mathrm{dt}$; (d) $\mathrm{Au}-\mathrm{dt}-\mathrm{CdS}-\mathrm{dt}-\mathrm{CdS}$.

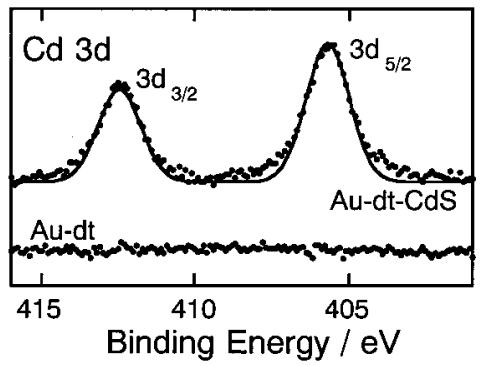

Figure 6. Narrow-scan XP spectra of $\mathrm{Cd} 3 \mathrm{~d}$ region of $\mathrm{Au}-\mathrm{dt}$ and $\mathrm{Au}-\mathrm{dt}-\mathrm{CdS}$. Hexanedithiol was used as a binding layer.

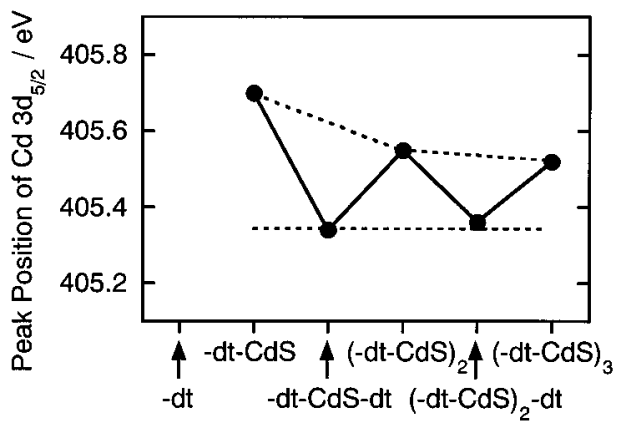

Figure 7. Changes in peak position of $\mathrm{Cd} 3 \mathrm{~d}_{5 / 3}$ during the process of composite film preparation.

tively, of the XPS characteristics due to AOT, showing that the attached AOT was replaced by the dithiol, as also detected by IRRAS. Almost the same results were obtained when decanedithiol was used as a binding layer. Therefore, the following discussion is made mainly for the hexanedithiol case for brevity.

Except for the case of $\mathrm{Au}-\mathrm{dt}$, unambiguous $\mathrm{Cd} 3 \mathrm{~d}_{5 / 2}$ and $\mathrm{Cd} 3 \mathrm{~d}_{3 / 2}$ peaks were observed at 405.7 and $412.5 \mathrm{eV}$, respectively (Figure 6), strongly suggesting the presence of $\mathrm{CdS}$ nanoparticles. The $\mathrm{Cd} 3 \mathrm{~d}$ peaks can be simulated with a single Gaussian component with an fwhm of $1.0 \mathrm{eV}$. The peak positions of Cd 3d, determined from the Gaussian fits, shifted to lower and higher binding energies by immersing in dithiol solution and CdS-nanoparticle dispersion, respectively (Figure 7 ), while the interval between $3 d_{5 / 2}$ and $3 d_{3 / 2}$ peaks was kept constant $(6.76 \mathrm{eV})$. The possibility of a shift caused by chargeup of the XPS samples is excluded, since the shift of peaks for other elements were not completely parallel. As schematically shown in Figure 8, there should be a few different types of $\mathrm{Cd}$ species located in the present composite films: surface $\mathrm{Cd}$ bound
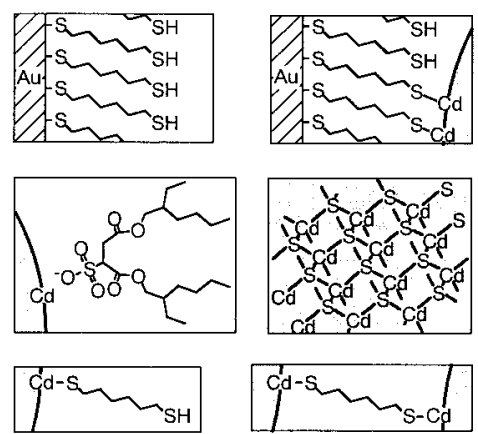

Figure 8. Proposed chemical structures giving different XP signals.

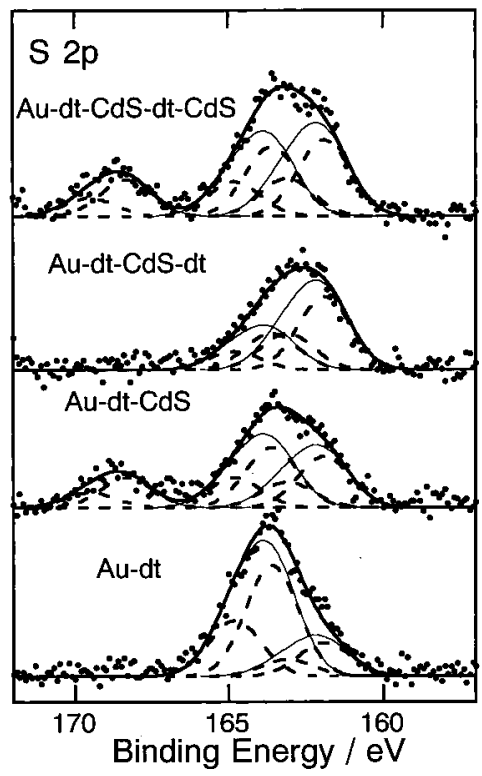

Figure 9. Narrow-scan $\mathrm{XP}$ spectra of $\mathrm{S} 2 \mathrm{p}$ region of $\mathrm{Au}-\mathrm{dt}, \mathrm{Au}-$ $\mathrm{dt}-\mathrm{CdS}$, and $\mathrm{Au}-\mathrm{dt}-\mathrm{CdS}-\mathrm{dt}$. Hexanedithiol was used as a binding layer. Dashed lines show three sets of doublets. Thin and thick lines represent the sum of each doublet and their total, respectively.

to thiol group or to AOT, and bulk $\mathrm{Cd}$ in the nanoparticle. We could not detect these species separately in Figure 7, but the alternate shift is interpreted qualitatively as follows. The $\mathrm{Cd}$ peaks might consist mainly of a signal of the bulk $\mathrm{Cd}$ species, and the change in apparent peak position is attributable to overlap of signals from the surface $\mathrm{Cd}$ species. It seems reasonable to assume that the sulfonate group in AOT affords ionic interaction with the surface $\mathrm{Cd}$ to result in higher binding energy, while the bulk $\mathrm{Cd}$ and the surface $\mathrm{Cd}$ bound to thiol give similar binding energy, as shown as a dotted line (lower) in Figure 7. Since the ratio of the AOT-bound Cd species to whole Cd giving an XP signal should be reduced along with the accumulation of layers, the peak position for samples before dithiol treatment shifts toward lower binding energy as shown as a dotted line (upper) in Figure 7.

Figure 9 shows narrow-scan XP spectra in the $\mathrm{S} 2 \mathrm{p}$ region. $\mathrm{The} \mathrm{Au}-\mathrm{dt}$ gave a peak centered at $164 \mathrm{eV}$. For the $\mathrm{Au}-\mathrm{dt}-$ $\mathrm{CdS}$, the peak was broadened and slightly shifted to lower binding energy with an increase in relative intensity of the shoulder at $162 \mathrm{eV}$. Furthermore, an additional peak was observed at $168 \mathrm{eV}$. These spectra were successfully reproduced by a combination of three sets of doublets, one for $168 \mathrm{eV}$ and the others for the $164 \mathrm{eV}$ peak, in which each doublet, corresponding to $\mathrm{S} 2 \mathrm{p}_{3 / 2}$ and $\mathrm{S} 2 \mathrm{p}_{1 / 2}$, consists of two Gaussian components separated by $1.2 \mathrm{eV}$ and of a 2:1 (lower to higher binding-energy component) intensity ratio. ${ }^{25,26}$ The position of each set of doublets was determined by referring to the reported 


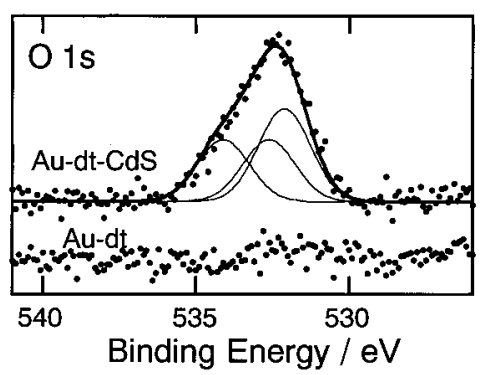

Figure 10. Narrow-scan XP spectra of $\mathrm{O} 1 \mathrm{~s}$ region of $\mathrm{Au}-\mathrm{dt}$ and $\mathrm{Au}-\mathrm{dt}-\mathrm{CdS}$. Hexanedithiol was used as a binding layer. Thin and thick lines show simulation of each oxygen species and their sum, respectively.

$2 \mathrm{p}_{3 / 2}$ chemical shift of a thiolate in alkanethiol SAM on gold $(\mathrm{RS}-\mathrm{Au}),{ }^{27}$ a thiol in polycrystalline sample $(\mathrm{RSH}),{ }^{27}$ and a sulfonate $\left(-\mathrm{SO}_{3}{ }^{-}\right)^{20}$ as $161.9,163.6$, and $168.3 \mathrm{eV}$, respectively. The first set of doublets should include sulfide ion $\left(\mathrm{S}^{2-}\right)$ in $\mathrm{CdS},{ }^{28}$ but it was practically impossible to distinguish it because of the nearly identical chemical shift $\left(161.5 \mathrm{eV}^{28}\right)$ and low signal-to-noise ratio of the spectra. In all the spectra in this study, the best fit was obtained by using a fwhm of $1.2 \mathrm{eV}$ for each peak.

The $\mathrm{Au}-\mathrm{dt}$ spectrum was simulated with two sets of doublets. The $S 2 p_{3 / 2}$ and $S 2 p_{1 / 2}$ peaks at 161.9 and $163.1 \mathrm{eV}$ correspond to thiolate, and those at 163.6 and $164.8 \mathrm{eV}$ to thiol. Thus, both types of sulfur species, i.e., $\mathrm{RS}-\mathrm{Au}$ and $\mathrm{RSH}$, were detected, suggesting that dithiol molecules are attached to gold at one end via an $\mathrm{S}-\mathrm{Au}$ bond with another end remaining unreacted. This model is consistent with the finding that the intensity of the thiol peak was much higher than that of the thiolate peak, since the thiol group is located at the outermost surface while the thiolate is covered with long-chain alkyl chains. For the hexanedithiol/Au system, Colvin et al. ${ }^{13}$ reported the appearance of a peak at a higher-energy region (around 169 $\mathrm{eV})$ and attributed it to X-ray-induced oxidation of the thiols. Such a phenomenon has not been observed in our study. Looping, i.e., both ends of dithiol molecule attached to gold, as they suggested, seems unlikely in our case.

$\mathrm{The} \mathrm{Au}-\mathrm{dt}-\mathrm{CdS}$ spectrum was compared with that of $\mathrm{Au}-$ $\mathrm{dt}$ to find some differences; the sulfonate peak (S(VI)) due to AOT appeared, and the intensity ratio of the thiolate and $\mathrm{S}^{2-}$ $\left(\mathrm{S}(-\mathrm{II})_{162}\right)$ peak to a thiol $\left(\mathrm{S}(-\mathrm{II})_{164}\right)$ peak increased. The latter finding is attributable to both increased intensity of $\mathrm{S}(-\mathrm{II})_{162}$ by attached $\mathrm{CdS}$ and a decrease in thiol moiety due to the binding with CdS. Shielding of dithiol SAM by the upper CdS layer is also plausible. Existence of disulfide RSSR, of which the binding energy has been reported as $163.0 \mathrm{eV},{ }^{29}$ cannot be ruled out. For the $\mathrm{Au}-\mathrm{dt}-\mathrm{CdS}-\mathrm{dt}$, a peak due to sulfonate disappeared, and the $\mathrm{S}(-\mathrm{II})_{162} / \mathrm{S}(-\mathrm{II})_{164}$ ratio increased further. At present we cannot exclude the other reasons for the latter result, but formation of lateral interparticle bonding through $\mathrm{Cd}-$ $S-\mathrm{R}-S-\mathrm{Cd}$ can account for this.

No appreciable peaks were observed in the $\mathrm{O} 1 \mathrm{~s}$ region for the $\mathrm{Au}-\mathrm{dt}$ (Figure 10). In the $\mathrm{Au}-\mathrm{dt}-\mathrm{CdS}$ spectrum, a broad and slightly distorted peak at $530-536 \mathrm{eV}$ is assignable to three overlapped peaks of the oxygen species. Peak simulation was achieved by using three Gaussian components with an fwhm of $1.2 \mathrm{eV}$, corresponding to the ester moiety $(-\mathrm{CO}-\mathrm{O}-\mathrm{C}-$ and $-\mathrm{CO}-\mathrm{O}-\mathrm{C}-$ ) and sulfonate $\left(-\mathrm{SO}_{3}{ }^{-}\right)$in AOT, on the assumption that the peak-area ratio is proportional to a stoichiometric ratio of $2: 2: 3$. The peak positions of these oxygen species $(534.1,532.6$, and $532.1 \mathrm{eV})$ were in good agreement with reported values: 533.9 and $532.4 \mathrm{eV}$ for poly(methyl

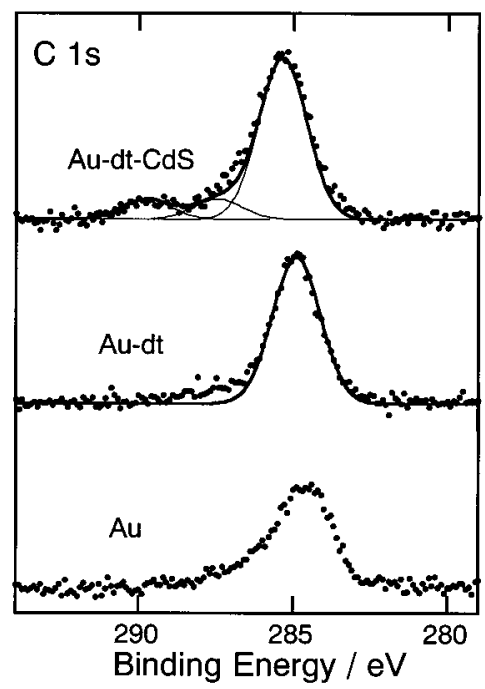

Figure 11. Narrow-scan XP spectra of $C$ 1s region of $A u, A u-d t$ and $\mathrm{Au}-\mathrm{dt}-\mathrm{CdS}$. Hexanedithiol was used as a binding layer.

methacrylate) and $531.9 \mathrm{eV}$ for $\mathrm{RSO}_{3} \mathrm{Na}^{20}$ The reasonable fit to the experimental result shows that the $\mathrm{O} 1 \mathrm{~s}$ peak is assigned to AOT.

Figure 11 shows narrow-scan XP spectra in the $\mathrm{C} 1 \mathrm{~s}$ region. For $\mathrm{Au}-\mathrm{dt}$, a peak could be fitted with a single Gaussian component centered at $284.9 \mathrm{eV}$ with an fwhm of $1.1 \mathrm{eV}$ without considering an asymmetric parameter. The peak is assignable to the carbon atoms in the dithiol molecule. A distorted small contamination peak appearing in the $\mathrm{Au}$ spectrum might not give any effects on the $\mathrm{Au}-\mathrm{dt}$ spectrum. For $\mathrm{Au}-\mathrm{dt}-\mathrm{CdS}$, a peak was reproduced by combination of three Gaussian components with an fwhm of $1.1 \mathrm{eV}$. The main component peaked at $285.3 \mathrm{eV}$ is assigned to the aliphatic hydrocarbon moiety of the AOT molecule. A higher-binding-energy tail has been deconvoluted into two components at 287.4 and $289.7 \mathrm{eV}$, attributable to the ester moiety $(-\mathrm{CO}-\mathrm{O}-\mathrm{C}-$ and $-\mathrm{CO}-\mathrm{O}-$ $\mathrm{C}-$, respectively). The peak-area ratio is proportional to the stoichiometric ratio of 16:2:2 in the AOT molecule. The binding energies have been reported as $284.6 \mathrm{eV}$ for polyethylene, 286.7 $\mathrm{eV}$ for $\mathrm{MeCH}_{2} \mathrm{OCOMe}$, and $289.0 \mathrm{eV}$ for MeCOOEt. ${ }^{20}$ The fitting required a shift of these peaks by $0.7 \mathrm{eV}$, though the reason is unclear at present. Anyway, the reasonable fit to the experimental result suggests that the $C 1 \mathrm{~s}$ peak is assignable to AOT. The peak profiles of $\mathrm{Au}-\mathrm{dt}-\mathrm{CdS}-\mathrm{dt}$ and $\mathrm{Au}-\mathrm{dt}-$ $\mathrm{CdS}-\mathrm{dt}-\mathrm{CdS}$ were quite similar to those of $\mathrm{Au}-\mathrm{dt}$ and $\mathrm{Au}-$ $\mathrm{dt}-\mathrm{CdS}$, respectively.

The above results are summarized as follows. The $\mathrm{Au}-\mathrm{dt}$ samples gave two-component $\mathrm{S} 2 \mathrm{p}$ and one-component $\mathrm{C} 1 \mathrm{~s}$ signals, all of which were attributable to dithiol SAM. For Au$\mathrm{dt}-\mathrm{CdS}$, signals from $\mathrm{CdS}$ and AOT were observed; the appearance of $\mathrm{Cd} 3 \mathrm{~d}$ peaks confirmed the existence of $\mathrm{CdS}$ and the appearance of one-component hexavalent $S 2 p$, threecomponent $\mathrm{O} 1 \mathrm{~s}$, and three-component $\mathrm{C} 1 \mathrm{~s}$ signals were of the AOT molecule. These AOT signals assigned with $\mathrm{Au}-$ $\mathrm{dt}-\mathrm{CdS}$ disappeared in the $\mathrm{Au}-\mathrm{dt}-\mathrm{CdS}-\mathrm{dt}$ spectra. The AOT signals appeared again, and the CdS signals increased by further treatment $(\mathrm{Au}-\mathrm{dt}-\mathrm{CdS}-\mathrm{dt}-\mathrm{CdS})$. These were in good agreement with our proposed model shown in Figure 1.

The depth profile of the composite films was obtained by measuring the XP spectra with a different takeoff angle, which is the angle between the surface and the direction of photoelectrons detected by analyzer. Although changes in spectra due to X-ray-induced damage were appreciable, unambiguous tendencies were found. Figure 12 shows the atomic ratio of 

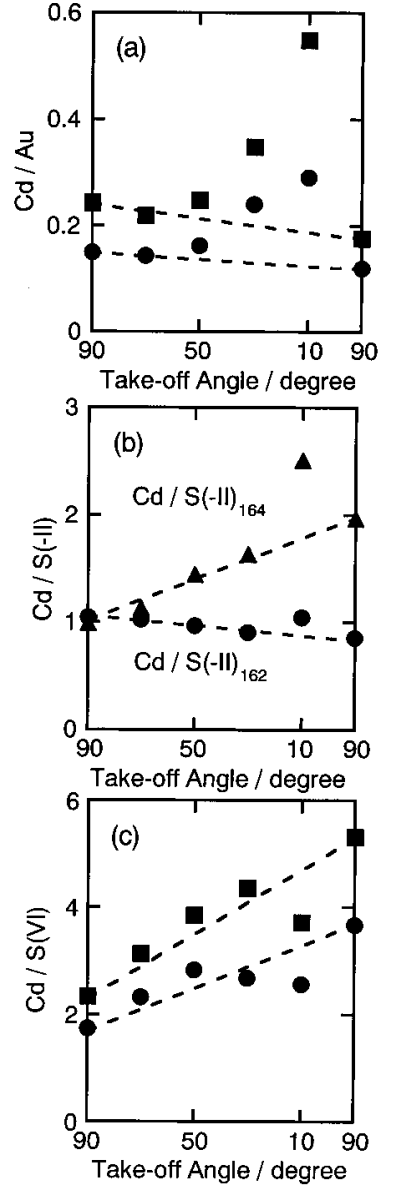

Figure 12. Dependence of atomic ratio of (a) $\mathrm{Cd} / \mathrm{Au}$, (b) $\mathrm{Cd} / \mathrm{S}(-\mathrm{II})$,

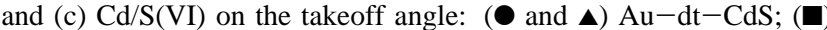
$\mathrm{Au}-\mathrm{dt}-\mathrm{CdS}-\mathrm{dt}-\mathrm{CdS}$.

$\mathrm{Cd} / \mathrm{Au}, \mathrm{Cd} / \mathrm{S}(-\mathrm{II})$ and $\mathrm{Cd} / \mathrm{S}(\mathrm{VI})$ as a function of the takeoff angle. To extract the angle-dependent response from X-rayinduced damage, the measurements at $90^{\circ}$ were carried out at the beginning (left) and end (right) of each series of measurements. Appreciable differences in two $90^{\circ}$ data, especially for $\mathrm{Cd} / \mathrm{S}(\mathrm{VI})$, should be due to the X-ray-induced damage, but we can see the angle-dependent response as a deviation from linear lines connecting these end points. For the following detailed investigation, it should be noted that the signal-to-noise ratio and intensity of $S 2 p$ signals were much lower than those of $\mathrm{Au} 4 \mathrm{f}$ and $\mathrm{Cd} 3 \mathrm{~d}$. A Cd/Au ratio for $\mathrm{Au}-\mathrm{dt}-\mathrm{CdS}$ and $\mathrm{Au}-$ $\mathrm{dt}-\mathrm{CdS}-\mathrm{dt}-\mathrm{CdS}$ was shown in Figure 12a. The ratio increased with a decrease of the takeoff angle, showing that $\mathrm{CdS}$ nanoparticles are located upside of $\mathrm{Au}$. In the case of $\mathrm{Au}-$ $\mathrm{dt}-\mathrm{CdS}-\mathrm{dt}-\mathrm{CdS}$, the ratio was a little larger at $90^{\circ}$ (left side) and increased more sharply, showing a larger average distance between $\mathrm{Cd}$ and $\mathrm{Au}$ in this sample. This is consistent with the proposed structure in which the second CdS layer is fabricated upside of the first $\mathrm{CdS}$ layer. The $\mathrm{Cd} / \mathrm{S}(-\mathrm{II})_{162}$ ratio, where $\mathrm{S}(-\mathrm{II})_{162}$ involves both $\mathrm{S}^{2-}$ and thiolate $(\mathrm{R} S-\mathrm{Au}$ and/or $\mathrm{R} S-$ $\mathrm{Cd})$, remained almost unity at larger takeoff angles and increased at small takeoff angle (Figure 12b). Assuming that the $\mathrm{Cd} / \mathrm{S}^{2-}$ ratio for the small $\mathrm{CdS}$ particles is independent of the takeoff angle, the observed angle-dependent $\mathrm{Cd} / \mathrm{S}(-\mathrm{II})_{162}$ ratio reflects the angle-dependent $\mathrm{Cd} /$ thiolate ratio. As shown in Figure $12 \mathrm{~b}$, the $\mathrm{Cd} / \mathrm{S}(-\mathrm{II})_{164}$ ratio, where $\mathrm{S}(-\mathrm{II})_{164}$ corresponds to thiol $(\mathrm{RSH})$, increased with a decrease of the takeoff angle. Thus, we can conclude that the Cd layer is located on the dithiol SAM layer. On the other hand, the $\mathrm{Cd} / \mathrm{S}(\mathrm{VI})$ ratio was nearly constant at larger takeoff angles and decreased at smaller takeoff angles.
This is compatible with the proposed structure of the composite film where CdS nanoparticles are surrounded by AOT; at least there should be AOT on the outermost surface. A little larger ratio of $\mathrm{Cd} / \mathrm{S}(\mathrm{VI})$ for the $\mathrm{Au}-\mathrm{dt}-\mathrm{CdS}-\mathrm{dt}-\mathrm{CdS}\left(2.4\right.$ at $\left.90^{\circ}\right)$ compared with that for the $\mathrm{Au}-\mathrm{dt}-\mathrm{CdS}\left(1.7\right.$ at $\left.90^{\circ}\right)$ is also accounted for by the structure illustrated in Figure 1d. AOT giving an $\mathrm{S}(\mathrm{VI})$ signal is present only on the second $\mathrm{CdS}$ nanoparticle layer, while both $\mathrm{CdS}$ layers cause the $\mathrm{Cd}$ signal.

As depicted in Figure $12 \mathrm{~b}$, the $\mathrm{Cd} / \mathrm{S}(-\mathrm{II})_{162}$ ratio was almost 1. Since $\mathrm{Cd} / \mathrm{S}(-\mathrm{II})_{162}$ contains thiolate bound to $\mathrm{CdS}$ and $\mathrm{S}^{2-}$ in CdS and since there should be appreciable amounts of such thiolate species binding $\mathrm{CdS}$ to the substrate, the ratio should be less than unity. However, as described in the Experimental Section, the composition of CdS nanoparticle was Cd-rich, and this may compensate to give nearly equal atomic amounts. On the other hand, the surface of a 3-nm-diameter CdS nanoparticle, consisting of $285 \mathrm{CdS}$ units as described in the previous section, can adsorb ca. 120 AOT molecules. ${ }^{23}$ This roughly agrees with the $\mathrm{Cd} / \mathrm{S}(\mathrm{VI})$ ratio of ca. 2, as shown in Figure 12c. A ratio $\mathrm{O} / \mathrm{S}(\mathrm{VI})$ was obtained as $7-8$ in the measurements of varying takeoff angles, being consistent with the ratio in the AOT molecule of 7 .

Surface Concentration of CdS Nanoparticles. ICP-MS measurements gave the average surface concentration of cadmium atoms on the samples. A typical result was $8.7 \times 10^{14}$ atoms $\mathrm{cm}^{-2}$ for a single layer of CdS nanoparticles, which was independent of the chain length of alkanedithiols. The estimated number of CdS units in a 3-nm-diameter particle is 285 by calculation from the volume ratio of the particle to the unit cell. Consequently, the above-mentioned results should correspond to $3.0 \times 10^{12}$ particles $\mathrm{cm}^{-2}$, or to the surface area of the substrate per each CdS nanoparticle of $3.3 \times 10^{-13} \mathrm{~cm}^{2}$ particle ${ }^{-1}$. This is close to a calculated value, $3.6 \times 10^{-13} \mathrm{~cm}^{2}$ particle $^{-1}$, by assuming two-dimensional packing of 3-nm CdS particles surrounded by the $1.5-\mathrm{nm}$-thick AOT layer, ${ }^{23}$ i.e., average interparticle (center to center) distance of $6 \mathrm{~nm}$. For $\mathrm{Au}-\mathrm{dt}-\mathrm{CdS}-\mathrm{dt}-\mathrm{CdS}$ with hexanedithiol, a concentration of $5.4 \times 10^{12}$ particles $\mathrm{cm}^{-2}$, which was ca. 1.8 times larger than that for $\mathrm{Au}-\mathrm{dt}-\mathrm{CdS}$, was obtained. With decanedithiol, however, a concentration of $6.0 \times 10^{12}$ particles $\mathrm{cm}^{-2}$ was almost 2 times larger than that of $\mathrm{Au}-\mathrm{dt}-\mathrm{CdS}$. These ratios of CdS particles between first and second layers are in good agreement with those estimated from the intensities of the AOT peaks in IRRAS.

Layer-by-Layer Assembly of Composite Layers. All the results described above revealed the layer-by-layer assembling process and the structure of composite layers as shown in Figure 1. FT-IRRAS and XPS results showed the behavior of dithiols and AOT during the composite-film formation process, in which AOT molecules covering $\mathrm{CdS}$ nanoparticles were substituted by thiol molecules at the immersion step. ICP-MS measurements gave quantitative information on the amount of attached $\mathrm{CdS}$ particles, which corresponded reasonably to a monolayer of nanoparticles for a step of immersion in CdS-nanoparticle dispersion. XP spectra also supported this, and the depth profiles confirmed the layer-by-layer structure of the composite films. Thus, thin composite films of well-ordered layer-bylayer structure have been prepared by a feasible wet (chemical) process: "dipping".

Photoelectrochemical Properties of Composite Layers. Because of the properties reflecting the structure of composite film shown above, photoelectrochemical measurements were carried out. Under the present conditions of a slightly anodic bias $(0 \mathrm{mV}$ vs $\mathrm{Ag} / \mathrm{AgCl})$, an anodic photocurrent was observed 


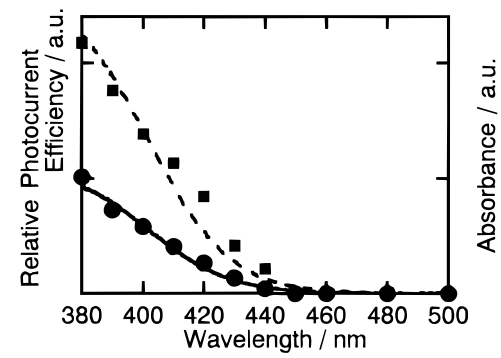

Figure 13. Action spectra of composite films and absorption spectra of CdS-nanoparticle dispersion before being immobilized. Circles and squares correspond to the relative photocurrent efficiency of $\mathrm{Au}-\mathrm{dt}-$ $\mathrm{CdS}$ and $\mathrm{Au}-\mathrm{dt}-\mathrm{CdS}-\mathrm{dt}-\mathrm{CdS}$, respectively, and solid and dashed lines show the absorption spectrum on different scales.

under illumination $(\lambda \lesssim 450 \mathrm{~nm})$, while a negligible dark current could be seen. The magnitude of the anodic photocurrent reached a steady state in a few seconds after commencement of illumination, and this steady-state current was used for characterization. The relative photocurrent efficiency, which was calculated by dividing the steady-state photocurrent by the number of photons of the incident light, depended on the wavelength of monochromatic light. As shown in Figure 13, the action spectrum for $\mathrm{Au}-\mathrm{dt}-\mathrm{CdS}$ was in good agreement with the absorption spectrum of CdS-nanoparticle dispersions before being immobilized onto the substrate. This indicates that the observed photoinduced current is caused by photoabsorption of $\mathrm{CdS}$ to produce excited electron-positive-hole pairs in nanoparticles, and also that $\mathrm{CdS}$ nanoparticles in the composite film keep their size as in their dispersion, without mutual aggregation of nanoparticles. It is commonly observed for n-type semiconductor electrodes that the photogenerated positive hole oxidizes triethanolamine adsorbed on the CdS surface and, in turn, the photoexcited electron is injected into the gold substrate to result in an anodic photocurrent without appreciable change in CdS. ${ }^{15,16}$ The action spectrum for $\mathrm{Au}-\mathrm{dt}-\mathrm{CdS}-$ $\mathrm{dt}-\mathrm{CdS}$ is also shown in Figure 13. The relative photocurrent efficiency was approximately twice as much as that of $\mathrm{Au}-$ $\mathrm{dt}-\mathrm{CdS}$ in the whole wavelength range. As shown in the preceding section, $\mathrm{CdS}$ nanoparticles are in monolayers, and therefore, only a small portion of incident light is absorbed. The doubling of efficiency is attributed to an increased number of photons absorbed by the second CdS layer. Details of the photoelectrochemical properties are under investigation.

\section{Conclusion}

We have prepared and characterized a composite thin film consisting of monolayers of $\mathrm{CdS}$ nanoparticles and alkanedithiol. The layer-by-layer structure and mechanism of film fabrication were confirmed by XPS, FT-IRRAS, and ICP-MS. Photocurrent measurements revealed that the monolayers of $\mathrm{CdS}$ nanoparticles were immobilized without mutual aggregation of particles. Detailed characterization of electrochemical, photoelectrochemical, and photochemical properties, which may reflect the thus clarified structure, as well as development of other semiconductor nanoparticle films, is now under investigation.
Acknowledgment. This work was partly supported by a Grant-in-Aid for Priority-Area-Research from the Ministry of Education, Science, Sports, and Culture, Japan (No. 08247201). We are grateful to Professor Katsuaki Shimazu, Division of Material Science, Graduate School of Environmental Earth Science, Hokkaido University, for use of the XPS instrument, to Dr. Sadamu Yamagata, Division of Sanitary Engineering, Graduate School of Engineering, Hokkaido University, for help in the ICP-MS measurements, and to Professor Masakazu Iwamoto, Catalysis Research Center, Hokkaido University, for discussion of the ICP-MS measurements.

\section{References and Notes}

(1) Henglein, A. Chem. Rev. 1989, 89, 1861.

(2) Hagfeldt, A.; Grätzel, M. Chem. Rev. 1995, 95, 49.

(3) Alivisatos, A. P. Science 1996, 271, 933.

(4) Alivisatos, A. P. J. Phys. Chem. 1996, 100, 13226.

(5) Spanhel, L.; Haase, M.; Weller, H.; Henglein, A. J. Am. Chem. Soc. 1987, 109, 5649.

(6) Steigerwald, M. L.; Alivisatos, A. P.; Gibson, J. M.; Harris, T. D.; Kortan, R.; Muller, A. J.; Thayer, A. M.; Duncan, T. M.; Douglass, D. C.; Brus, L. E. J. Am. Chem. Soc. 1988, 110, 3046.

(7) Murray, C. B.; Norris, D. J.; Bawendi, M. G. J. Am. Chem. Soc 1993, 115,8706 .

(8) Vossmeyer, T.; Katsikas, L.; Giersig, M.; Popovic, I. G.; Diesner K.; Chemseddine, A.; Eychmüller, A.; Weller, H. J. Phys. Chem. 1994, 98,7665 .

(9) Tian, Y.; Wu, C.; Fendler, J. H. J. Phys. Chem. 1994, 98, 4913.

(10) Kotov, N. A.; Dékány, I.; Fendler, J. H. J. Phys. Chem. 1995, 99 , 13065.

(11) Gao, M.; Zhang, X.; Yang, B.; Li, F.; Shen, J. Thin Solid Films 1996, 284-285, 242.

(12) Ulman, A. An Introduction to Ultrathin Organic Films from Langmuir-Blodgett to Self-Assembly; Academic Press: San Diego, CA, 1991.

(13) Colvin, V. L.; Goldstein, A. N.; Alivisatos, A. P. J. Am. Chem. Soc. 1992, 114, 5221 .

(14) Katari, J. E. B.; Colvin, V. L.; Alivisatos, A. P. J. Phys. Chem. 1994, 98, 4109. 11182

(16) Ogawa, S.; Hu, K.; Fan, F.-R. F.; Bard, A. J. J. Phys. Chem. B 1997, 101, 5707.

(17) Miyake, M.; Matsumoto, H.; Nishizawa, M.; Sakata, T.; Mori, H.; Kuwabata, S.; Yoneyama, H. Langmuir 1997, 13, 742.

(18) Nakanishi, T.; Ohtani, B.; Uosaki, K. Jpn. J. Appl. Phys. 1997, 36, 4053.

(19) Nakanishi, T.; Ohtani, B.; Shimazu, K.; Uosaki, K. Chem. Phys. Lett. 1997, 278, 233.

(20) Wagner, C. D.; Riggs, W. M.; Davis, L. E.; Moulder, J. F.; Muilenberg, G. E. Handbook of X-ray Photoelectron Spectroscopy; PerkinElmer Corporation: Eden Prairie, MN, 1979.

(21) Wagner, C. D.; Davis, L. E.; Zeller, M. V.; Taylor, J. A.; Raymond,

R. M.; Gale, L. H. Surf. Interface Anal. 1981, 3, 211.

(22) Lippens, P. E.; Lannoo, M. Phys. Rev. B 1989, 39, 10935.

(23) Zulauf, M.; Eicke, H.-F. J. Phys. Chem. 1979, 83, 480

(24) Porter, M. D.; Bright, T. B.; Allara, D. L.; Chidsey, C. E. D. J. Am. Chem. Soc. 1987, 109, 3559.

(25) Hutchison, J. E.; Postlethwaite, T. A.; Murray, R. W. Langmuir 1993, 9, 3277.

(26) Fritz, M. C.; Hähner, G.; Spencer, N. D.; Bürli, R.; Vasella, A. Langmuir 1996, 12, 6074.

(27) Laibinis, P. E.; Whitesides, G. M.; Allara, D. L.; Tao, Y.-T.; Parikh, A. N.; Nuzzo, R. G. J. Am. Chem. Soc. 1991, 113, 7152.

(28) Meissner, D.; Benndorf, C.; Memming, R. Appl. Surf. Sci. 1987, $27,423$.

(29) Bain, C. D.; Biebuyck, H. A.; Whitesides, G. M. Langmuir 1989, 5,723 . 